\title{
Elongated Styloid Process Revisited
}

\section{Anand Acharya}

\section{ABSTRACT}

Elongated styloid process is one of the many causes of pain in throat. Yet, it is often overlooked. When the throat looks normal on examination, the entity should be kept in mind, to clinch the diagnosis. Management and review of literature are discussed.

Keywords: Eagle syndrome, Elongated styloid process, Foreign body sensation, Stylalgia.

How to cite this article: Acharya A. Elongated Styloid Process Revisited. Int J Phonosurg Laryngol 2015;5(1):15-16.

\section{Source of support: Nil}

\section{Conflict of interest: None}

\section{CASE REPORT}

A 22-year-old lady presented to the ENT Outpatient Department of Government Medical College, Nizamabad, Telangana, with complaints of pain in the throat, radiating to the left ear and a feeling of foreign body sensation in the throat. There was no history of fever, cough, nasal complaints, hoarseness of voice, ear discharge, etc. There was no history of renal disease or previous surgery in the throat. She was not addicted to tobacco chewing or alcohol. She reported to the ENT department after having no relief from treatment undertaken elsewhere.

Routine ENT examination did not reveal any significant positive findings. Oral cavity examination revealed normal tonsils, posterior pharyngeal wall, no palpable lymph nodes in the neck. Nose and ears examination revealed no abnormality.

Palpation of the tonsillar fossae revealed a palpable styloid process on the left-side. Patient reported to have tenderness and radiating pain to ear on left-side when palpation was done. Infiltrating the left tonsillar fossa with $1 \%$ lignocaine led to disappearance of the symptoms. A diagnosis of elongated styloid process on the left-side was made.

\section{Associate Professor}

Department of Otorhinolaryngology, Government Medical College, Nizamabad, Telangana, India

Corresponding Author: Anand Acharya, Associate Professor Department of Otorhinolaryngology, Government Medical College, Nizamabad, Telangana, India, Phone: 04027038242 e-mail: acharya.is.anand@gmail.com
For confirmation, lateral $\mathrm{X}$-ray radiograph and an orthopantomogram was requested which revealed an elongated styloid process on the left side (Fig. 1).

The patient was advised tonsillectomy and excision of elongated styloid process as the definitive treatment.

Preoperative hematological tests and serum calcium level (to rule out dystrophic calcification) revealed all parameters within normal limits.

Patient was operated under general anesthesia. After tonsillectomy, the left tonsillar fossa was palpated to confirm the elongation of styloid process. Blunt dissection was done to expose the styloid process to the maximum extent. Periosteum was elevated on all sides of the elongated process. Excision of the styloid process was done with bone nibbler after releasing all the attachments to the tip of styloid process (Fig. 2). The excised process was about $1.5 \mathrm{~cm}$ (Fig. 3). The exposed area was sutured with absorbable sutures. Patient was followed up for 6 months and there was no recurrence of symptoms.

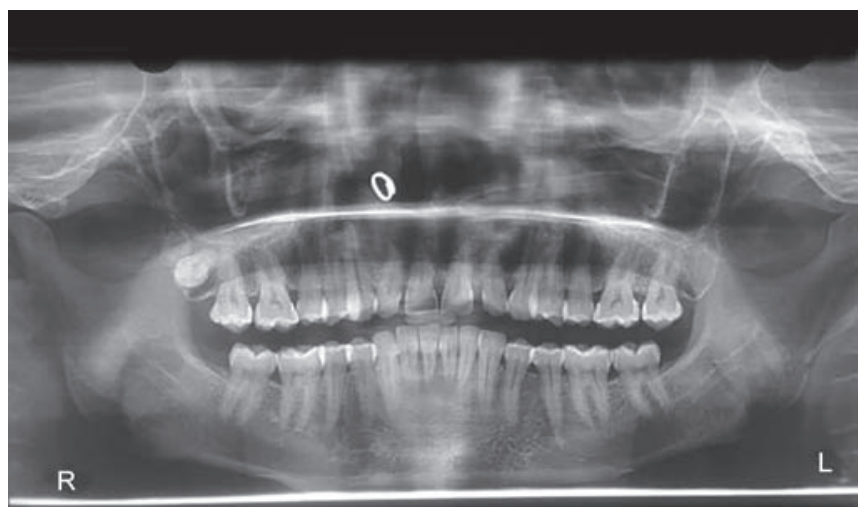
$\mathrm{L}$

Fig. 1: Left-side styloid process

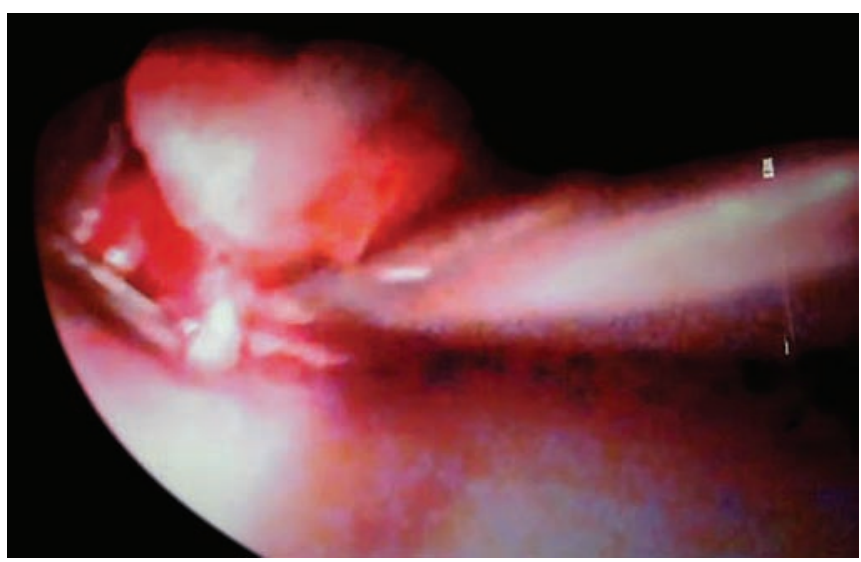

Fig. 2: Exposure of styloid process 


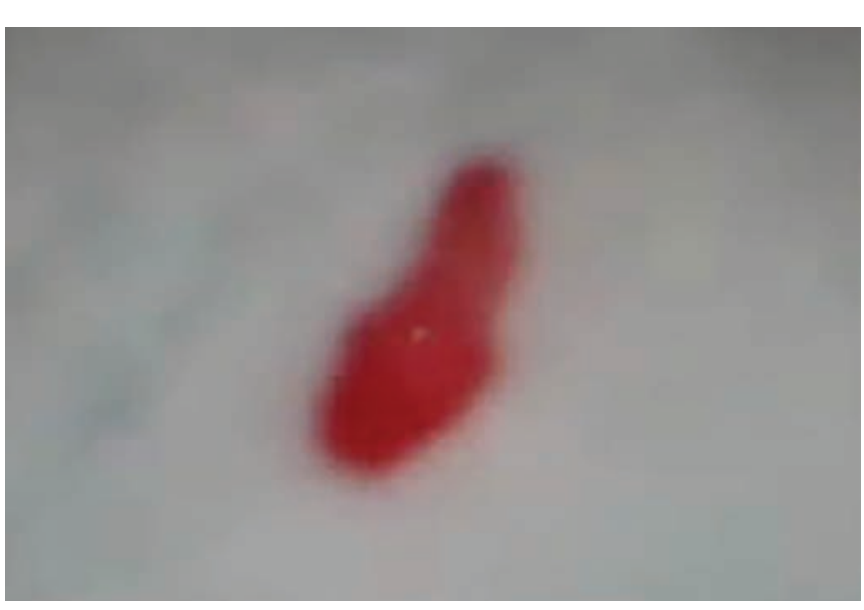

Fig. 3: Excised styloid process

\section{DISCUSSION}

Watt W Eagle was the first person to describe an elongated styloid process causing pain in the throat in 1937. Hence, the disease is eponymously called as 'Eagle's syndrome'.

Elongated styloid process is normally 2 to $2.5 \mathrm{~cm}$. It is a long round bone attached to the inferior part of temporal bone in front of the stylomastoid foramen surrounded by nerves and vessels. It is said to be elongated when the length exceeds by $3 \mathrm{~cm}$ and beyond by various authors. ${ }^{5}$ However, the length is not always associated with symptoms. Asymptomatic patients with elongated styloid process were detected on incidental X-rays of lateral view of neck.

The presentation with symptoms is more in the 20 to 30 years age group, and more in females who outnumber males by $3: 1$.

Clinical presentation is by vascular and neural compression of the surrounding structures around the styloid process. Apart from feeling a foreign body sensation, lump in throat, headache and radiating pain to the ipsilateral side while swallowing, headache on rotation of the head to the side and giddiness on rotation of the head are also the modes of presentation. Studies on dystrophic calcification which could cause elongation of styloid process by calcification of the stylohyoid ligament did not reveal elevated calcium or phosphorus in all patients. ${ }^{1} \mathrm{~A}$ cause and effect relationship was not ascertained.

Diagnosis is based on palpation of the tonsillar fossae which reveals duplication of the symptoms, ${ }^{3}$ relief of symptoms with local infiltration with anesthetic injections and demonstration on plain X-ray lateral view neck or OPG or CT of the neck.

Differential diagnosis includes all the causes of pain in the neck and head viz., unerupted wisdom teeth, temporal arteritis, glossopharyngeal neuralgia, etc.

Operations for excising the elongated styloid process is by intraoral pharyngeal route or external route. Majority of the studies done employed the intraoral route.
This route is less time consuming, easy exposure, and early rehabilitation are the advantages. It is claimed that this route leads to deep neck space infections and difficult to control bleeding if vascular structures are injured. The external route is claimed to be less risky, less injury to the neural and vascular structures, and proper surgical exposure. It needs skilled exposure from the neck, delayed recovery and skill to repair the major vascular arteries if injured. External route is safer despite external scar and deeper dissection was surgery of choice for some. ${ }^{6,7}$ Advantages claimed are control over neural and vascular structures which are encountered in this area.

Surgeons who employ the intraoral route have ingeniously developed various methods of exposure to avoid injury to adjacent vital structures by using ring curettes around the styloid process during dissection. Large number of studies have shown complication-free followup of cases operated by intraoral route. ${ }^{4}$

\section{SUMMARY}

Elongated styloid process (Eagle's syndrome) is a clinical entity which presents with pain and feeling of foreign body in throat and is a rare cause of headache and giddiness on turning the head. It can be diagnosed easily by digital palpation of tonsillar fossae, and can be documented by radiography. A high degree of suspicion is needed when throat looks normal in patients complaining of foreign body sensation or odynophagia despite treatment medically. Surgery of the elongated process can be easily done by intraoral route and is a fairly reliable procedure without long-term sequelae.

\section{ACKNOWLEDGMENTS}

I thank the Superintendent, Government General Hospital, Nizamabad, Telangana, for allowing me to use the hospital records for publication.

\section{REFERENCES}

1. Gorke C, Sisnan Y, Siphioglu M. Styloid process elongation or Eagle's syndrome: is there any role for ectopic calcification? Eur J Dent 2008 July;2:224-228.

2. Eagle WW. Elongated styloid process: report of two cases. Archives of Otolaryngol 1937 May;25(5):584-587.

3. Russell TE. Eagle's syndrome: diagnostic considerations and report of a case. J Am Dent Assoc 1977 Mar;94(3):548-550.

4. Prasad KC, Kamath MP, Reddy KJM, Raju K, Agarwal S. J Oral Maxillofac Surg 2002 Feb;60(2):171-175.

5. Murtagh RD, Caracciolo JT, Fernandez G. CT findings associated with Eagle syndrome. Am J Neuroradiol 2001;22(7):1401-1402.

6. Lindeman P. The elongated styloid process as a cause of throat discomfort: four case reports. J Laryngol Otol 1985 May;99(5):505-508.

7. Strauss M, Zohar Y, Laurian N. Elongated styloid process syndrome intraoral vs external approach for styloid surgery. Laryngoscope 1985;95(8):976-979. 